\title{
Fetal Thoracoamniotic Shunting in a Case of Congenital Pulmonary Airway Malformations with Hydrops Fetalis
}

\author{
Hayase Nitta, $\mathrm{MD}^{1} \quad$ Yusuke Taira, $\mathrm{MD}^{1} \quad$ Tadatsugu Kinjo, MD, $\mathrm{PhD}^{1} \quad$ Yukiko Chinen, $\mathrm{MD}^{1}$
} Hitoshi Masamoto, MD, PhD ${ }^{1}$ Naoya Sanabe, $\mathrm{MD}^{2}$ Hideki Goya, $\mathrm{MD}^{3}$ Tomohide Yoshida, MD, $\mathrm{PhD}^{3}$ Rika Sugibayashi, MD ${ }^{4}$ Masahiro Sumie, MD ${ }^{4,5}$ Seiji Wada, MD, PhD ${ }^{4}$ Haruhiko Sago, MD, $\mathrm{PhD}^{4}$ Yoichi Aoki, MD, PhD ${ }^{1}$

\footnotetext{
${ }^{1}$ Department of Obstetrics and Gynecology, University of the Ryukyus, Okinawa, Japan

${ }^{2}$ Department of Digestive and General Surgery, University of the Ryukyus, Okinawa, Japan

${ }^{3}$ Department of Pediatrics, Graduate School of Medicine, University of the Ryukyus, Okinawa, Japan

${ }^{4}$ Center of Maternal-Fetal, Neonatal and Reproductive Medicine, National Center for Child Health and Development, Tokyo, Japan

${ }^{5}$ Department of Obstetrics, Fukuoka Children's Hospital,

Fukuoka, Japan
}

Am J Perinatol Rep 2017;7:e185-e187.

\begin{abstract}
Address for correspondence Yoichi Aoki, MD, PhD, Department of Obstetrics and Gynecology, Graduate School of Medicine, University of the Ryukyus, 207 Uehara Nishihara, Okinawa 903-0215, Japan (e-mail: yoichi@med.u-ryukyu.ac.jp).
\end{abstract}

\author{
Abstract \\ Keywords \\ - CPAM \\ - thoracoamniotic \\ shunting \\ - hydrops fetalis \\ - high-frequency \\ oscillation \\ - nitric oxide
}

\begin{abstract}
Aim We report a case of congenital pulmonary airway malformation (CPAM) with hydrops in which the fetus underwent thoracoamniotic shunting.

Case Report A 40-year-old (G1P1) woman was diagnosed with a macrocystic CPAM. Thoracoamniotic shunting was performed at 19 weeks of gestation but not well drained and was successfully performed again at 23 weeks. However, the CPAM volume ratio, abdominal circumference, and amniotic fluid index started increasing from 28 weeks and hydrops worsened. The insufficient shunting and the fetal cardiac failure had to be considered. At 32 weeks, a male infant with general edema and massive ascites was born weighing 3,362 $\mathrm{g}(+4.79 \mathrm{SD})$ with Apgar scores of 2 and 4. The infant was intubated and high-frequency oscillation and nitric oxide therapies were instituted. The resection of CPAM was performed on day 2. Nasal continuous positive airway pressure was instituted on day 16 . The infant was discharged and prescribed with home oxygen therapy (HOT) on day 65 . The infant was able to leave the HOT at 30 months and is currently 34 months of age in good condition.

Conclusion Fetal thoracoamniotic shunting may be life-saving in CPAM complicated by hydrops and that this treatment might be sufficient to cure the child.
\end{abstract}

Congenital pulmonary airway malformation (CPAM) of the lung, also known as congenital cystic adenomatoid malformation, is a rare abnormality ( 1 out of every 15,000 live births), which is easily diagnosed by prenatal ultrasonography. ${ }^{1,2}$ Very large lesions of CPAM carry a significant risk of causing both pulmonary hypoplasia due to compression of lung tissue ${ }^{3}$ and fetal hydrops, probably due to impaired cardiac function as a result of mediastinal shift and compression of the vena cava or cardiac tamponade. The prognosis is markedly worsened if hydrops develops, which has been received

March 10, 2017

accepted

August 8, 2017
DOI https://doi.org/

10.1055/s-0037-1606830. ISSN 2157-6998.
Copyright @ 2017 by Thieme Medical Publishers, Inc., 333 Seventh Avenue, New York, NY 10001, USA. Tel: +1(212) 584-4662.
License terms

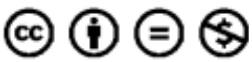


reported in as many as 14 to $30 \%$ of the cases referred to fetal therapy centers. ${ }^{4-6}$ CPAM volume ratio (CVR) was calculated preoperatively following the publication of this predictor in $2002^{7}$ and has been proposed as an index to predict the development of hydrops in cases where this condition exists. If the CVR is more than 1.6, the risk of hydrops is approximately $75 \%$.

Fetal thoracoamniotic shunting was offered in the case of macrocystic lesions with fetal hydrops or signs of evolving hydrops such as ascites, and lesions that were very large (CVR $>1.6$ ), rapidly increasing in size, or were associated with polyhydramnios. ${ }^{8}$ Subsequently, it was clear that in these cases, fetuses can be successfully treated with the much less invasive approach of thoracoamniotic shunting. A systematic review revealed an improved survival rate of $62 \%$ ( 15 of 24 ) in treated hydropic fetuses versus 3\% (1 of 33 ) in the untreated ones (odds ratio, 19.28; 95\% confidence interval, 3.7-101). ${ }^{9}$ In a recent review of a total of 110 fetuses with CPAM treated with thoracoamniotic shunting between 1987 and 2016, the survival rate was $77 \%$ (53 of 69 ) for hydropic and $90 \%$ (37 of 41) for nonhydropic fetuses. ${ }^{10}$

We report a case of CPAM (macrocystic type, Stocker type 1) of the right lung with hydrops fetalis in which the fetus underwent thoracoamniotic shunting.

\section{Case Report}

A 40-year-old (G1P1) woman, in her second pregnancy after a cesarean section due to a weak pain that impeded a vaginal delivery, was referred to the University of the Ryukyus Hospital at 19 weeks of gestation for the evaluation of a fetus with a lesion of the right lung. An ultrasound examination revealed a $39 \times 37 \times 49-\mathrm{mm}$ sized monocystic lesion of the right lung. The heart was shifted to the left, and the amniotic fluid index (AFI) was $9.14 \mathrm{~cm}$. Magnetic resonance imaging (MRI) revealed fetal ascites and subcutaneous edema of the fetal head (-Fig. 1). The presentations were consistent with a macrocystic CPAM, Stocker type 1, and the CVR was 1.95.

Fetal therapy was considered owing to the large CVR, severe mediastinal shift, polyhydramnios, and ascites. Thoracoamniotic shunting was performed at 19 weeks of gestation but not well drained because of increased CVR thereafter. Shunting was successfully performed again at 23 weeks with reduction of the cystic mass; the procedure was done at the National Center for Child Health and Development Hospital (Tokyo, Japan). However, the CVR, abdominal circumference (AC), and AFI started increasing from 28 weeks of gestation. The CVR was 2.6; AC was $22 \mathrm{~mm}$ with massive fetal ascites and worsened subcutaneous edema; AFI was $32 \mathrm{~cm}$ at 30 weeks of gestation (-Fig. 2); and premature rupture of the membrane occurred. Thereafter, the CVR repeatedly increased and decreased. The insufficient shunting and the fetal cardiac failure had to be considered. Fetal well-being was secured under close cardiotocography and biophysical profile scoring monitoring. At $32^{4 / 7}$ weeks of gestation, after awaiting fetal maturation, an elective cesarean section was performed. A male infant with

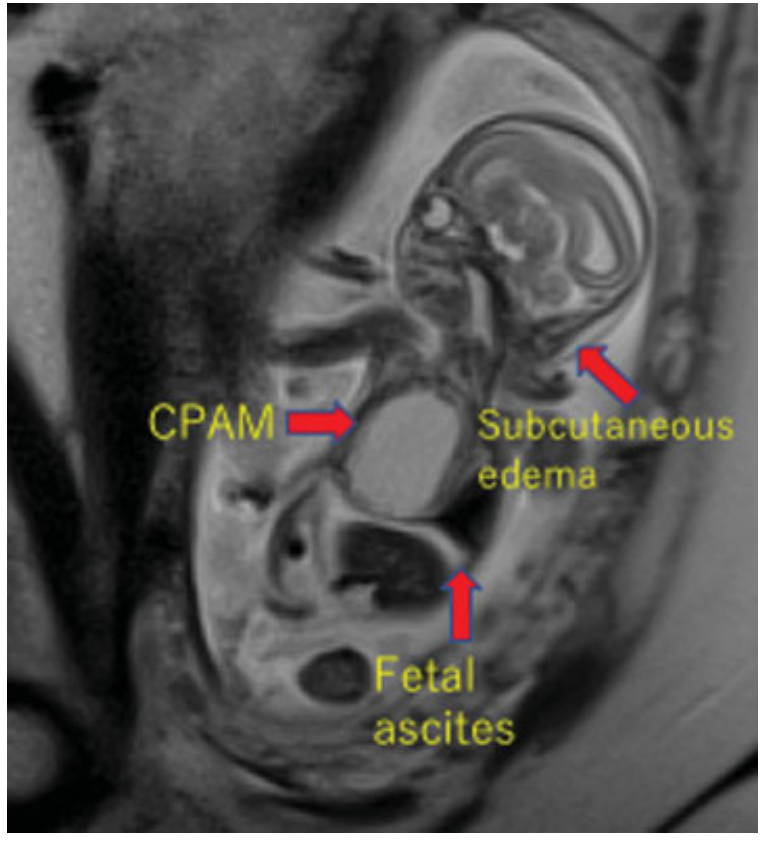

Fig. 1 Magnetic resonance imaging at 19 weeks of gestation shows large cystic mass in the right lung, fetal ascites, and subcutaneous edema of the fetal head (arrows). CPAM, congenital pulmonary airway malformation.

general edema and massive ascites was born weighing 3,362 $\mathrm{g}(+4.79 \mathrm{SD})$ with Apgar scores of 2 and 4.

The infant was intubated immediately, surfactant was administered, and $40 \mathrm{~mL}$ of ascites was removed. Ten minutes after birth, high-frequency oscillation and nitric oxide therapies were instituted as supportive care for stabilizing the infant because of profound persistent pulmonary

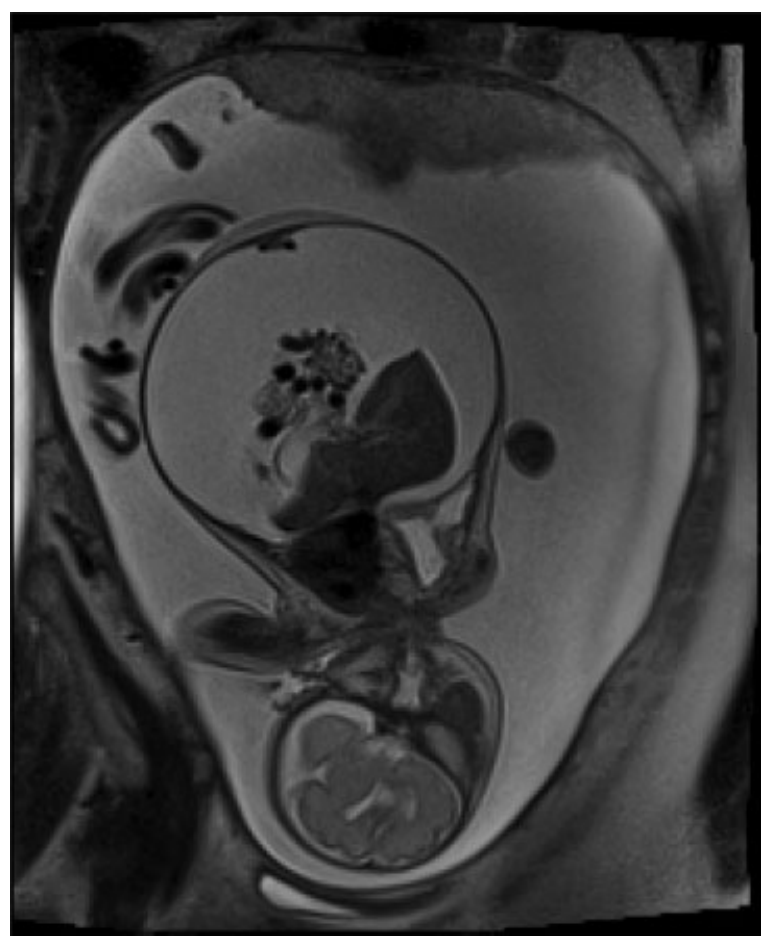

Fig. 2 Magnetic resonance imaging at 31 weeks of gestation shows marked hydrops fetalis and polyhydramnios. 
hypertension. The resection of CPAM (right middle lobectomy) was uneventfully performed on day 2 . The closure of PDA was observed by indomethacin administration on day 12. Extubation was performed, and nasal continuous positive airway pressure was instituted on day 16 . The infant was discharged and prescribed with home oxygen therapy (HOT) on day 65. No other anomaly was observed. The infant was able to leave the HOT at 30 months and is currently 34 months of age with good condition.

\section{Discussion}

In our case, CPAM was diagnosed in the fetus at 19 weeks of gestation by ultrasonography and MRI. As the role of thoracoamniotic shunting in macrocystic lung lesions associated with hydrops is well accepted, ${ }^{8-10}$ thoracoamniotic shunting was performed soon after the diagnosis of CPAM with hydrops. After the second shunting, the CVR decreased once, thereafter with repeated increases and decreases. The hydrops and polyhydramnios worsened. Insufficient drainage was considered. One of the arguments for shunting large lesions is the prevention of pulmonary hypoplasia, ${ }^{3,11}$ and suggested prognostic markers include size and type of lesion, the presence of mediastinal shift, polyhydramnios, hydrops, and CVR. ${ }^{7}$ Our case included all of these; however, atleast mediastinal compression was relieved by the shunting.

Hydrops fetalis is defined as a state of excessive fluid accumulation in the extravascular compartment of the fetus, leading to widespread soft-tissue edema and/or collection of fluid in two or more fetal serous body cavities. The association of CPAM and nonimmune fetal hydrops is reported to carry a very poor prognosis for survival. ${ }^{12}$ In cases in which the mechanism of hydrops involves high-output cardiac failure ${ }^{13}$ in addition to mediastinal compression, ${ }^{14}$ the development of hydrops fetalis is probably secondary to cardiac failure due to left-to-left shunting that may occur in the presence of an anomalous systemic artery and venous drainage via pulmonary or systemic veins. ${ }^{12}$ We could not find any vascular anomalies in our case. The inferior vena cava occlusion and poor venous return because of mediastinal deviation were considered to be the causes of fetal subcutaneous edema and exacerbation of fetal ascites; however, no obvious cardiac preload was observed in the fetus by ultrasound examination. Repeated increase and decrease in CVR due to an imbalance in the pressure between the pulmonary cyst and excessive amniotic fluid indicated that the shunt functioned to the extent that it did not markedly worsen the fetal cardiac preload. This suggests the possibility that it might improve the prognosis of the fetus.

In our case, the fetus had a high risk of neonatal death and resuscitation maneuvers were particularly difficult. As a multidisciplinary group of medical specialists involving obstetricians, perinatologists, radiologists, pediatric surgeons, midwives, and nurses, we had weekly meetings during which decisions concerning management were made. The present case confirms that fetal thoracoamniotic shunting may be life-saving in CPAM complicated by hydrops and that this sole treatment might be sufficient to cure the child.

\section{Conflict of Interest}

The authors declare that there is no commercial association that might create a conflict of interest in connection with this manuscript.

Acknowledgments

The authors thank Enago (www.enago.jp) for the English language review.

\section{References}

1 Stocker JT, Madewell JE, Drake RM. Congenital cystic adenomatoid malformation of the lung. Classification and morphologic spectrum. Hum Pathol 1977;8(02):155-171

2 Stocker JT. Cystic lung disease in infants and children. Fetal Pediatr Pathol 2009;28(04):155-184

3 Davenport M, Warne SA, Cacciaguerra S, Patel S, Greenough A, Nicolaides K. Current outcome of antenally diagnosed cystic lung disease. J Pediatr Surg 2004;39(04):549-556

4 Adzick NS, Harrison MR, Crombleholme TM, Flake AW, Howell LJ. Fetal lung lesions: management and outcome. Am J Obstet Gynecol 1998;179(04):884-889

5 Miller JA, Corteville JE, Langer JC. Congenital cystic adenomatoid malformation in the fetus: natural history and predictors of outcome. J Pediatr Surg 1996;31(06):805-808

6 Grethel EJ, Wagner AJ, Clifton MS, et al. Fetal intervention for mass lesions and hydrops improves outcome: a 15-year experience. J Pediatr Surg 2007;42(01):117-123

7 Crombleholme TM, Coleman B, Hedrick H, et al. Cystic adenomatoid malformation volume ratio predicts outcome in prenatally diagnosed cystic adenomatoid malformation of the lung. J Pediatr Surg 2002;37(03):331-338

8 Schrey S, Kelly EN, Langer JC, et al. Fetal thoracoamniotic shunting for large macrocystic congenital cystic adenomatoid malformations of the lung. Ultrasound Obstet Gynecol 2012;39(05): 515-520

9 Knox EM, Kilby MD, Martin WL, Khan KS. In-utero pulmonary drainage in the management of primary hydrothorax and congenital cystic lung lesion: a systematic review. Ultrasound Obstet Gynecol 2006;28(05):726-734

10 Litwińska M, Litwińska E, Janiak K, Piaseczna-Piotrowska A, Gulczyńska E, Szaflik K. Thoracoamniotic shunts in macrocystic lung lesions: case series and review of the literature. Fetal Diagn Ther 2017;41(03):179-183

11 Dommergues M, Louis-Sylvestre C, Mandelbrot L, et al. Congenital adenomatoid malformation of the lung: when is active fetal therapy indicated? Am J Obstet Gynecol 1997;177(04):953-958

12 Morin L, Crombleholme TM, D'Alton ME. Prenatal diagnosis and management of fetal thoracic lesions. Semin Perinatol 1994;18 (03):228-253

13 Anandakumar C, Biswas A, Chua TM, et al. Direct intrauterine fetal therapy in a case of bronchopulmonary sequestration associated with non-immune hydrops fetalis. Ultrasound Obstet Gynecol 1999;13(04):263-265

14 Slotnick RN, McGahan J, Milio L, Schwartz M, Ablin D. Antenatal diagnosis and treatment of fetal bronchopulmonary sequestration. Fetal Diagn Ther 1990;5(01):33-39 